\title{
Quinolinium tribromide; a mild and very efficient oxidant in organic synthesis
}

\author{
Mohammad Joshaghani, ${ }^{\text {a,b }}$ Ezzat Rafiee, ${ }^{\text {a,b }}$ Fomaida Shahbazi, ${ }^{\text {a Hadi Jafari, }}$ \\ Saeedeh Amiri, ${ }^{a}$ and Masoomeh Omidi ${ }^{a}$ \\ ${ }^{a}$ Chemistry Department, Razi University, Kermanshah 67149, Iran \\ ${ }^{b}$ Kermanshah Oil Refining Company, Kermanshah, Iran \\ E-mail:MJosh@liverpool.ac.uk
}

\begin{abstract}
Quinolinium tribromide has been used for the symmetric oxidation of anilines and thiols to the corresponding hydrazines and disulfides, respectively. This oxidant shows an excellent reactivity and selectivity in mild reaction conditions.
\end{abstract}

Keywords: Thiol oxidation, amine oxidation, hydrazine, disulfide, tribromide

\section{Introduction}

Since the early introduction of quinolinium- and pyridinium tribromides as reagents for the bromination of double bonds, ${ }^{1}$ the application of this new category of the reagent was limited to pyridinium tribromide ${ }^{2-4}$ and no further example of the application of quinolinium tribromide has been recorded.

The oxidation of amines is a useful way for the synthesis of a variety of nitrogen-containing organic compounds. The reaction leads to different products depending on the nature of the oxidizing agents and type of amines. ${ }^{5}$ Azo derivatives are among the most common products obtained from the corresponding anilines using oxidizing agents such as diacetoxyiodobenzene, ${ }^{6}$ manganese dioxide, ${ }^{7}$ or silver(II) oxide. ${ }^{8}$ It is suggested that the reaction proceeds via a free radical mechanism, where the aniline is converted into a symmetrical $N, N$ '-diarylhydrazine and subsequently yields the corresponding azo compound on further oxidation. ${ }^{9}$ However, there is no report of the isolation of a hydrazine intermediate.

Recently, we reported that bipyridinium tribromide (BPHP), is a versatile oxidizing agent for the selective oxidative coupling of thiols. ${ }^{10}$ BPHP has two nitrogen atoms but CHN elemental analysis and also potentiometric studies showed that only one nitrogen atom is protonated. In

\footnotetext{
${ }^{*}$ Part of this work was presented at the $7^{\text {th }}$ Tetrahedron Symposium, Kyoto, Japan, 25-26 May 2006
} 
order to check the effects of the protonated heterocyclic nitrogen atom of BPHP on the rate of conversion and selectivity, we decided to extend our study to a structure analogous to BPHP, with only one nitrogen atom. We now report the use of quinolinium tribromide (QTB) as an excellent oxidant in the oxidation of anilines and thiols to the corresponding coupling products, as shown in Scheme 1.

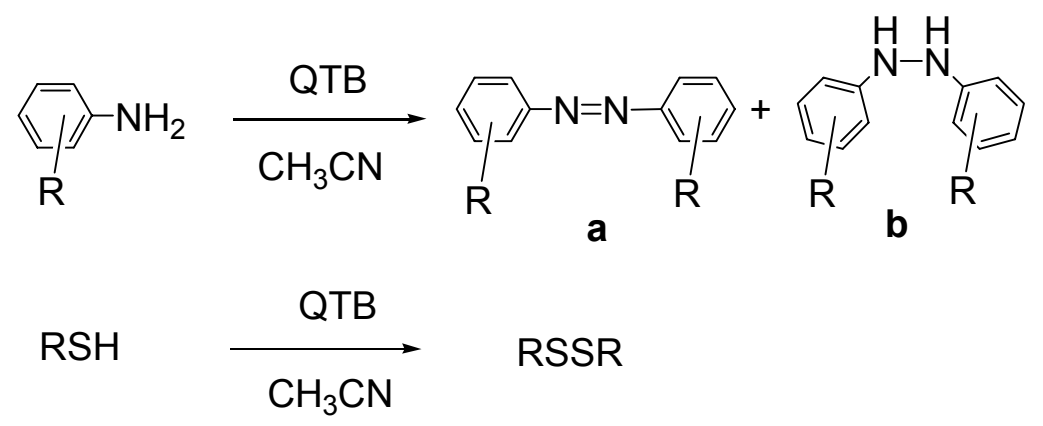

\section{Scheme 1}

\section{Results and Discussion}

\section{Oxidation of anilines}

The early application of QTB was limited to bromination of double bonds. ${ }^{1}$ In continuation of our interest in the potential of tribromide oxidants, we found that QTB could selectively oxidize anilines. Initial optimization was carried out using aniline for which most expected products were commercially available. Three products were obtained; two of them were characterized as azobenzene and $N, N^{\prime}$-diphenylhydrazine using TLC and GC chromatography. The third product was isolated carefully using plate chromatography and characterized as $p$-anilinoaniline (Scheme 2 , compound c). In its IR spectrum, two strong and medium peaks at 3320 and $3415 \mathrm{~cm}^{-1}$ were assigned for the $v(\mathrm{~N}-\mathrm{H})$ of $\mathrm{N}-\mathrm{H}$ and $\mathrm{NH}_{2}$ groups. $\mathrm{CHN}$ elemental analysis was also aided for determining the molecular formula of this product. Because of the protection of the para position in para-substituted anilines and probably steric effects of other positions, the latter product was not observed in the substituted anilines.

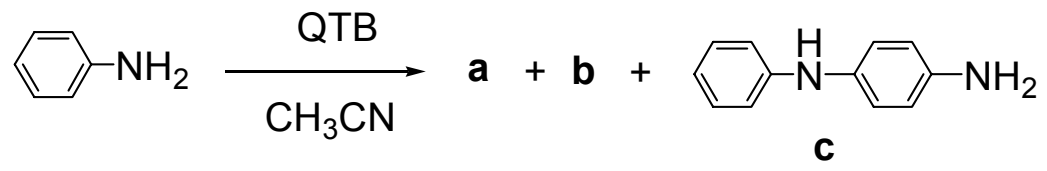

\section{Scheme 2}

The oxidation of substituted anilines with this reagent is summarized in Table 1. A series of substituted anilines was reacted with equimolar amounts of the reagent to afford the 
corresponding azo- and hydrazine products within $40 \mathrm{~min}$. The products were characterized using ${ }^{1} \mathrm{H}-\mathrm{NMR}$ and IR spectra and comparison with authentic samples. ${ }^{11-14}$

Table 1. Oxidation of anilines by QTB ${ }^{\mathrm{a}}$

\begin{tabular}{|c|c|c|c|c|}
\hline \multirow{2}{*}{ Entry } & \multirow{2}{*}{ Aniline } & \multicolumn{3}{|c|}{ Yield $(\%)^{b}$} \\
\hline & & Azo (a) & Hydrazine (b) & Amine (c) \\
\hline 1 & $\mathrm{H}_{2}$ & 55 & 20 & 15 \\
\hline 2 & $\mathrm{Ph}$ & - & 35 & \\
\hline 3 & $\mathrm{Ie}_{2}$ & - & - & - \\
\hline 4 & 4e & - & 55 & \\
\hline 5 & & 65 & & \\
\hline 6 & $\mathrm{NH}_{2}$ & 45 & 40 & \\
\hline 7 & & 55 & 30 & \\
\hline 8 & & 50 & 30 & \\
\hline 9 & $-\mathrm{NH}_{2}$ & 75 & & \\
\hline 10 & & 80 & & \\
\hline
\end{tabular}

${ }^{\text {a }}$ All reactions were carried out at room temperature using equimolar amounts of oxidant and substrate in acetonitrile. All products were identified by their IR and NMR spectral data and comparison of their mp with published data. ${ }^{11-14}$

${ }^{\mathrm{b}}$ Isolated yields.

All hydrazine products were characterized as being similar to $N, N^{\prime}$-diphenylhydrazine by a broad to sharp singlet in their ${ }^{1} \mathrm{H}$ NMR spectra at about 3.5-4.5 ppm with relative intensity equal to 2 protons. ${ }^{11}$ Some hydrazine products had an additional characterized signal; for example, a sharp singlet at $2.81 \mathrm{ppm}$ with relative intensity of 6 protons was a assigned for two methyl groups attached to nitrogen in methylphenylhydrazine (Table 1, entry 4). For bis-(2ethylphenyl)hydrazine (Table 1, entry 5), the ethyl group has well-known triplet and quartet signals at 1.33 and $2.62 \mathrm{ppm}$ due to methyl and methylene protons, respectively. Such additional characterization peaks was observed in bis-(3,4-dimethoxyphenyl)hydrazine (Table 1, entry 9) at $3.78 \mathrm{ppm}$ with relative intensity equal to 12 protons which was assigned for methyl protons of 
methoxy groups. IR spectra of the aromatic hydrazines show a strong peak at about 3250-3400 $\mathrm{cm}^{-1}$ due to stretching frequency of N-H groups and a strong signal about $1350 \mathrm{~cm}^{-1}$ due to $v(\mathrm{~N}-$ $\mathrm{N})$ stretching frequency. Reactivity of the hydrazine products toward common oxidants to producing the corresponding orange-red azo compounds was also chosen as another decisive factor for their characterization. ${ }^{15} \mathrm{UV}$-vis spectra of the azo products showed a characterized broad peak at about $450-500 \mathrm{~nm}$. A medium to strong peak at about $1500 \mathrm{~cm}^{-1}$ in the IR spectra was also assigned for the stretching frequency of $\mathrm{N}=\mathrm{N}$ bond.

Wang et al. ${ }^{9}$ proposed a free radical mechanism, in which the aniline is converted into a symmetrical $N, N$ '-diarylhydrazine and subsequently yields the corresponding azo compound on further oxidation. Although the preparation of hydrazine- and azo- derivatives is a good criterion for a free radical pathway, we decided to check the mechanism. The reaction was completely inhibited in the presence of acrylonitrile as radical scavenger. Also, the same products were obtained in dried acetonitrile and an inert atmosphere of nitrogen. These results, and the absence of oxo- products strongly supported a free radical mechanism for the oxidation of anilines using QTB.

\section{Oxidation of thiols}

Selective oxidative coupling of thiols to the corresponding disulfides is of practical importance both in biochemistry and in synthetic chemistry. ${ }^{16}$ The utility of the BPHP ${ }^{10}$ in the oxidation of thiols to the corresponding disulfides encouraged us to test similar reactions using QTB as oxidant in acetonitrile, as well as in solvent-free conditions. In the ${ }^{1} \mathrm{H}$ NMR and IR spectra of the disulfides, the signals belongs to the $\mathrm{S}-\mathrm{H}$ group was absent which is a good criterion for complete reaction of the initial thiols. The ${ }^{1} \mathrm{H}$ NMR and IR spectra as well as melting points of disulfides are similar to those reported in the literature. ${ }^{16-21}$

The results are shown in Table 2. Aromatic and aliphatic thiols react well to afford the corresponding disulfides in high- to excellent yields, independent of electronic and steric effects of the substituents, (Table 2, entries 1-9). Interestingly, no oxidation of the amine group was observed in the case of entry 9. Therefore, the high selectivity and ease of oxidation are remarkable advantages of this reagent.

Another important advantage of this reagent is seen in the oxidation of the mercaptobenzimidazole, and 2-mercaptothiobenzimidazole (Table 2, entries 12,13) to their corresponding disulfides in only 5 minutes at room temperature, in excellent yields. This oxidation was also performed under solvent-free conditions, where the disulfides were obtained completely within 5-10 min. The results show that under solvent free conditions, the reaction times are shorter. This advantage, and also the cheaper and environmentally cleaner reaction in the absence of organic volatile solvents make this a valuable method for the preparation of disulfides. In recent years, much effort has been invested in the preparation of disulfides in solvent- free conditions, but most of them have employed some volatile organic solvents such as dichloromethane in the work-up step. ${ }^{22}$ The green chemistry with ether as a work- up solvent is an advantage of our work. In addition, in comparison with two structurally analogous 
tribromides, PHP (pyridinium hydrobromide perbromide) and BPHP (bipyridinium hydrobromide perbromide), this reagent is more reactive and oxidize thiols in shorter reaction time.

Table 2. Oxidation of thiols by QTB under solvent free conditions ${ }^{\text {a }}$

\begin{tabular}{llll}
\hline Entry & Time (min) & RS-SR Yield (\%) \\
\hline 1 & $10(10)$ & $95(95)$ \\
\hline
\end{tabular}

${ }^{a}$ All reactions were carried out at room temperature using an oxidant-to-substrate molar ratio of 1:2. The values in the parentheses are from the reaction in acetonitrile. All products were identified by their IR and NMR spectral data and comparison of their mp with published data. ${ }^{16-}$ 21

${ }^{\mathrm{b}}$ Isolated yields.

Finally, the selectivity of the reagent was investigated using equimolar amounts of two thiols with one molar equivalent of the reagent in solution and the solid phase (Table 2). In acetonitrile solution (Table 3, entries 1-4), only one of the starting thiols was converted into the corresponding symmetrical disulfides and the other could be isolated almost in quantitative yield while in the solid phase, both thiols were oxidized to the corresponding symmetrical disulfide (Table 3, entries 5-8). In neither conditions was cross-coupling observed. 
Table 3. Competitive oxidative coupling of thiols with QTB ${ }^{\text {a }}$

(mis)

${ }^{a}$ All reactions carried out at RT with oxidant: substrate molar ratio 1:2. Entries 1-4 carried out in $\mathrm{CH}_{3} \mathrm{CN}$ solution; entries 5-8, solvent-free conditions. All products identified by IR and NMR data, and comparison of mp with published data. ${ }^{\mathrm{b}}$ Isolated yields. 


\section{Conclusions}

The oxidation of anilines and thiols to the corresponding symmetrical azo- and hydrazine derivatives and disulfides using QTB takes place in high to excellent yields under mild conditions and very short reaction times. It also should be emphasized that the reactions could be performed cleanly, and stopped at the desired stage, without any over-oxidation, even in the presence of other potentially oxidizable functional groups. Compared to BPHP, the QTB shows shorter and cleaner reactions, which may be due to inductive effects of the free nitrogen of BPHP. ${ }^{10}$ Because of wide application of pyridinium hydrobromide perbromide in organic synthesis, QTB can be potentially a well alternative.

\section{Experimental Section}

General Procedures. Melting points were recorded on an Electrothermal apparatus and are uncorrected. All chemicals are commercially available and used without further purification except for liquid anilines, which were distilled before use. ${ }^{1} \mathrm{H}$ NMR spectra were recorded on a Bruker Avance $200 \mathrm{MHz}$ NMR spectrometer. Elemental analysis was performed using a CHN Heraus Rapid model. UV-visible spectra were recorded using an Agilent 8453 UV-visible diode array spectrometer in $1 \mathrm{~cm}$ matched silica cells. Thin layer chromatography was performed using silica gel Fluorescent $254 \mathrm{~nm}(0.2 \mathrm{~mm})$ on precoated aluminum plates.

Preparation of quinolinium hydrobromide perbromide (QTB). To a flask containing quinoline $(5 \mathrm{ml}, 42 \mathrm{mmol})$ cooled in an ice-salt bath, hydrobromic acid $(7 \mathrm{ml}, 62 \mathrm{mmol})$ was added slowly. The reaction was stirred for about $5 \mathrm{~min}$, and then bromine $(3.2 \mathrm{ml}, 62 \mathrm{mmol})$ was added dropwise. The temperature was maintained at about $-5{ }^{\circ} \mathrm{C}$. A bulky orange solid was formed immediately which was dried in vacuo, $m \mathrm{p} 140-143{ }^{\circ} \mathrm{C}$ (decomp.). Yield $10.9 \mathrm{~g} \mathrm{(70 \% ).}$ Anal. Calc. For $\mathrm{C}_{9} \mathrm{H}_{8} \mathrm{NBr}_{3}$ : C, $29.19 \%$; H, $2.16 \%$; N, $3.78 \%$. Found: C, $29.52 \%$; H, $2.33 \%$; N, $3.58 \%$.

General procedure for oxidation of anilines (Table 1, entry 1). To a stirred solution of the aniline $(0.3 \mathrm{ml}, 3.0 \mathrm{mmol})$ in acetonitrile $(5 \mathrm{ml})$, QTB $(1.0 \mathrm{~g}, 3.0 \mathrm{mmol})$ was added, and the mixture was stirred at RT for $40 \mathrm{~min}$. The reaction mixture was treated with a 1:1 mixture of ether and water $(2 \mathrm{ml})$. The organic phase was extracted with ether $(3 \times 10 \mathrm{ml})$. The organic layers were combined and dried over anhydrous $\mathrm{MgSO}_{4}$. The products were isolated using plate chromatography. The crude third product was chromatographed on silica gel (hexane: ethyl acetate 6:1) to give $P$-anilinoaniline which was characterized using $\mathrm{CHN}$ elemental analysis and ${ }^{1} \mathrm{H}$ NMR $\left[\left(\mathrm{CCl}_{4}\right), \delta(\mathrm{ppm}): 3.6-3.9\left(2 \mathrm{H}, \mathrm{bs}, \mathrm{NH}_{2}\right), 4.1(1 \mathrm{H}, \mathrm{s}, \mathrm{NH}), 6.2(4 \mathrm{H}, \mathrm{s}\right.$, aromatic protons), 6.4-6.6 $(3 \mathrm{H}, \mathrm{m}$, aromatic protons), 7.0-7.3 $(2 \mathrm{H}, \mathrm{m}$, aromatic protons). Azobenzene was chromatographed on silica gel (benzene) and was characterized using ${ }^{1} \mathrm{H}$ NMR, IR and UV-vis 
spectroscopies. ${ }^{16-21}$ Diphenylhydrazine was chromatographed in a similar way using ethyl acetate: $n$-heptane $(1: 2)$.

General procedure for oxidation of thiols in acetonitrile solution (Table 2, entry 2). To a stirred solution of 4-chlorothiophenol $(0.29 \mathrm{~g}, 2.0 \mathrm{mmol})$ in acetonitrile $(5 \mathrm{ml})$, QTB $(0.33 \mathrm{~g}, 1.0$ mmol) was added, and the mixture was stirred at RT for $10 \mathrm{~min}$. A yellowish solid was formed and was treated with a 1:1 mixture of ether and water $(2 \mathrm{ml})$. The reaction mixture was extracted with ether $(3 \times 10 \mathrm{ml})$. The organic layers were combined and dried over anhydrous $\mathrm{MgSO}_{4}$. The solvent was removed by rotary evaporator to afford the corresponding disulfide in $100 \%(0.26 \mathrm{~g})$ yield, IR (KBr), $v\left(\mathrm{~cm}^{-1}\right)$ : 3050(w), $1560(\mathrm{~m}), 1450(\mathrm{~s}), 1370(\mathrm{~s}), 1080(\mathrm{~s}), 1000(\mathrm{~s}), 810(\mathrm{~s}), 770(\mathrm{~m})$, 730(s). ${ }^{1} \mathrm{H} \mathrm{NMR}\left(\mathrm{CCl}_{4}\right), \delta(\mathrm{ppm}): 7.4(4 \mathrm{H}, \mathrm{s}) . \mathrm{mp} 72{ }^{\circ} \mathrm{C}\left(\right.$ lit. ${ }^{23} \mathrm{mp} 74{ }^{\circ} \mathrm{C}$ ).

General procedure for oxidative coupling of thiols under solvent-free conditions. A mixture of $1.0 \mathrm{mmol}$ of thiols and $0.5 \mathrm{mmol}$ of the reagent in a mortar was ground with a pestle for the length of time according to Table 2. After completion of the reaction, the mixture was extracted with ether. The solvent was evaporated and the crude product was either recrystallized or subjected to chromatography on silica gel to afford the pure product.

\section{Acknowledgements}

The authors are grateful to the Razi University Research Council and Kermanshah Oil Refining Company for the support of this work. M.J. is particularly grateful to Professors B. Movassagh, H. Firouzabadi, and I. Mohammadpoor-Baltork for their valuable comments.

\section{References and Footnotes}

1. Djerassi, C.; Scholz, C. R. J. Am. Chem. Soc. 1948, 70, 417.

2. (a) Fieser, L. F.; Fieser, M. Reagents for Organic Synthesis; Wiley: New York, 1967; Vol. 1, p. 967. (b) Arcus, C. L.; Strauss, H. E. J. Chem. Soc. 1952, 2669. (c) Fieser, L. F. J. Chem. Educ. 1954, 31, 291. (d) Kornfeld, E. C.; Fornefeld, E. J.; Kline, G. B.; Mann, M. J.; Morrison, D. E.; Jones, R. G.; Woodward, R. B. J. Am. Chem. Soc. 1956, 78, 3087. (e) Kowar, T.; LeGoff, E. Synthesis 1973, 112. 3. See for instance: (f) Perdman, M.; Farkos, E.; Fornefeld, E. J.; Kraay, R. J.; Tapala, R. T. J. Am. Chem. Soc. 1960, 82, 2402. (g) Johns, J. F. J. Org. Chem. 1966, 31, 3780. (h) Meyer, W. L.; Clemans, G. B.; Manning, R. A. J. Org. Chem. 1975, 40, 3686. (i) Uemoto, T.; Kawashima, T.; Sakata, Y.; Misumi, S. Tetrahedron Lett. 1975, 1005. (j) Sharma, V.; Sharma, P. K.; Banerji, K. K. J. Indian Chem. Soc. 2000, 77, 291. (k) Suri, D.; Banerji, K. K.; Kothari, S. J. Chem. Res. 1995 (S), 274; (M) 1734. (1) Goel, S.; Kothari, S.; Banerji, K. K. J. Chem. Res. 1996, (S), 230; (M) 1318. (m) Kothari, S.; Banerji, K. K. J. Chem. Res. 1999, (S), 476; (M) 2118. (n) Goswami, G.; Kothari, S.; Banerji, K. K. J. Chem. Res. 1999, (S), 176. (M) 813. (o) Si, A.; Nikalje, M. D.; Sudalai, A. 
Org. Lett. 1999, 1, 705. 5. (p) Piers, K.; Meimaroglou, C.; Jardine, R. V.; Brown, R. K. Can. J. Chem. 1963, 41, 2399. (q) Banks, R. E.; Haszeldine, R. N.; Latham, J. V.; Young, I. M. J. Chem. Soc. 1965, 594. (r) Reeves, W. P.; King, R. M., II Synth. Commun. 1993, 23, 855. (s) Reeves, W. P.; Lu, C. V.; Sculmeier, B.; Jonas, L.; Hatlevic, O. Synth. Commun. 1998, 28, 499. (t) Piers, K., Miemaroglou, C., Jardine, R. V., Brown, R. K. Can. J. Chem. 1963, 41, 2399.

3. Husstedt, U. J. U.; Schafer, H. J. Synthesis 1979, 964.

4. (a) Reeves, W. P., King, R. M., Synth. Commun. 1993, 23, 855. (b) Aoyama, T.; Takido, T.Y.; Kodomari, M. Tetrahedron Lett. 2005, 46, 1989. (c) Sayama, S.; Onami, T. Synlett 2004, 2739. (d) Córdoba, R.; Plumet, J. Tetrahedron Lett. 2002, 43, 9303.

5. Smith, M. B.; March, J. March's Advanced Organic Chemistry; Wiley-Interscience: New York, 2001, Chapter 19.

6. Pausacker, K. H. J. Chem. Soc. 1953, 1989.

7. Wheeler, J.; Morton, C. J.; Thomas, D. F. J. Chem. Soc. 1965, 2621.

8. Ortiz, B.; Villanuevaa, P.; Walls, F. J. Org. Chem. 1972, 37, 2748.

9. Wang, X.; Wang, Y.; Li, J.; Wang, C.; Duan, Z.; Zhang, Z. Indian J. Chem. 2000, 39B, 545.

10. Joshaghani, M.; Khosropour A. R.; Jafari, H.; Baltork, I. M. Phosphorus, Sulfur, and Silicon 2005, 180, 117-123.

11. Alberti, A.; Canè, F.; Dembech, P.; Lazzari, D.; Ricci, A.; Seconi, G. J. Org. Chem. 1996, 61, 1677.

12. Pouchert, C. J. The Aldrich Library of Infrared Spectra; Aldrich Chemical Company: Milwaukee, Third Ed., 1981.

13. Pouchert, C. J. The Aldrich Library of NMR Spectra; Aldrich Chemical Company: Milwaukee, Second Ed., 1983.

14. Dictionary of Inorganic Compounds; Chapman and Hall: New York, Fifth Ed., 1982.

15. Verma, K. K. Talanta 1979, 26, 257.

16. (a) Jocelyn, D. C. Biochemistry of the Thiol Group; Academic Press: New York, 1992; p 1;

(b) Propter, D. J.; J. Chem. Soc., Perkin Trans. 1, 2000, 835. (c) Capozzi, G.; Modena, G.; Patai, S. The Chemistry of the Thiol Group; Wiley: New York, 1974; p785. (d) Rao, K. R.; Kumar, H. M. S. Bioorganic and Med. Chem. Lett. 1991, 1, 507.

17. Hirano, M.; Yakabe, S.; Ando, K. I.; Morimoto, T. J. Chem. Res. (S) 1998, 816. Meshram, H. M.; Bandyopadhyay, A.; Reddy, G. S.; Yadav, J. S. Synth. Commun. 2000, 30, 701. Salehi, P.; Farrokhi, A.; Gholizadeh, M. Synth. Commun. 2001, 31, 2777. Firouzabadi, H.; Iranpoor, N.; Zolfigol, M. A. Synth. Commun. 1998, 28, 1179.

18. Wu, X; Rieke, D.; Zhu, L. Synth. Commun. 1996, 26, 191.

19. Hirano, M.; Yakabe, S.; Fukami, M.; Morimoto, T. Synth. Commun. 1997, 27, 2783.

20. Iranpoor, N.; Firouzabadi, H.; Pourali, A.R. Tetrahedron 2002, 58, 5179.

21. Wang, J. X.; Gao, L.; Huang, D. Synth. Commun. 2002, 32, 963.

22. Kesavan, V.; Bonnet-Delphon, D.; Bégué, J.P. Synthesis 2000, 223.

23. Huang, M.; Chan, C. C. Synthesis 1982, 1091. 